\title{
A Pace of Our Own? Becoming Through Speeds and Slows - Investigating Living Through Temporal Ontologies of The University
}

\author{
Malou Juelskjær ${ }^{1 *}$, Monika Rogowska-Stangret ${ }^{2}$
}

Published: October 30, 2017

\begin{abstract}
This article is concerned with new feminist materialism's transformatory ethical potential with regards to the (fast) neoliberal university. It is also shaped and inspired by Karen Barad's question: 'How can I be responsible for that which I love?' (Barad 2016). The text thus investigates possibilities of thinking through new materialist theorising and concepts for examining conditions of the $\mathrm{im} /$ possibilities of living live-able academic lives in current political climates. As a response to those conditions a cry for slowing down has surfaced and manifestos for slow scholarship, reading, pedagogy, professors have emerged. The fast-slow dualism seems to be of pivotal importance in the ongoing criticism of neoliberal universities. The authors share concerns expressed by 'slow professors', but at the same time they argue that slow movement in the academia reestablish a problematic dualistic approach. In the text criticism of binary conceptualisations is offered by arriving at ethical considerations (instead of tactical). The article is inspired by Donna Haraway's plea to 'stay with the trouble' (2016) to uncover the complex temporalities of the present and - possibly its subversive potential. Furthermore, while staying in this troublesome moment, the authors investigate temporal ontologies through the works of Gilles Deleuze and Félix Guattari (2007 [1980]), Henri Lefebvre (2004) and Barad (2012) - as well as the temporalities implied in the 'slow science movement'. Finally, the video art by Bill Viola is considered as a way of accessing problematics of shifting between 'fast' and 'slow'.
\end{abstract}

Keywords: slow science, ethics, new feminist materialisms, slow motion, university, neoliberalism

\section{INTRODUCTION}

This article is part of an ongoing series of conversations between the two authors - face-to-face in Warsaw, in Copenhagen and on Skype. In these conversations, we explore different possibilities for thinking through new materialist theorising and concepts, simultaneously examining the conditions of becoming/being/living/researching/teaching within academia, as well as the practices of academics, be it teaching and learning, researching, doing theory, practising thinking, discussing, engaging with theory, ideas, students, fellow researchers, selves, friends, family members, technologies, environments ${ }^{1}$.

Engaging with the new materialist conceptual framework, we wanted to approach the question of the $\mathrm{im} /$ possibilities of living live-able, learn-able, teach-able, and response-able academic lives in the current political climates. As stated by Rick Dolphijn and Iris van der Tuin, (2012), new materialisms are, among other things, 'pushing dualisms to an extreme' (Bergson [1986] 2004: 236). Dualisms such as body-mind, nature-culture, humananimal, organic-inorganic, theory-practice, are revisited to grasp the movement of differentiation, entanglements, and relationality. New materialist scholarship engages with capturing the beyond of dualisms and/or with tracing the conditions of $\mathrm{im} /$ possibilities of dualisms (new materialism is, of course, not alone in this). With relation to

\footnotetext{
${ }^{1}$ Our collaboration was made possible through the COST action 'New Materialism. Networking European Scholarship on 'How matter comes to matter". We presented a paper on the subject matter of this article, at the $7^{\text {th }}$ Annual Conference on the New Materialisms. Performing Situated Knowledges: Space, Time, Vulnerability, in Warsaw, 21 23 September 2016. Monika Rogowska-Stangret's contribution is funded by the grant from the Ministry of Science and Higher Education in Poland in the frames of the "National Programme for the Development of the Humanities" (2016-2019).
}

1 Associate professor at University of Aarhus, DENMARK

${ }^{2}$ Post-doctoral researcher at the Institute of Philosophy, $W$ arsaw University, POLAND

*Corresponding Author:malou@edu.au.dk 
living the academic life - taking into account the associated movements, sensations, and temporalities - we pose the question: Is there anything left of oppositional approach: in theory, in analysis, and in practice?

Along these lines, we investigate a dualism that has been haunting university life for some time: the duality of 'speeding up' and 'slowing down', of so-called 'fast' and 'slow' science. We want to address the temporal ontologies that drive and haunt university life and some of their possible effects. The tempo, the rhythms ${ }^{2}$, shape academic bodies and lives by shaping and orchestrating the processes we engage in, be it teaching and/or researching, and the 'products' that we as academics deliver ${ }^{3}$. We find this prism of fast-slow intriguing and important. Firstly, because the fast-slow dualism seems to be of pivotal importance in the ongoing criticism of neoliberal universities and in the process of searching for remedies. Secondly, we find the dualistic approach to fast-slow problematic, and theoretically and analytically underdeveloped. Finally, when thinking about movement, binary oppositions such as fast-slow seem to contradict the very nature of the imperceptibility of movement (as observed by Deleuze and Guattari 2007 [1980]: 280).

Furthermore, we aim to arrive at some ethical considerations (instead of tactical). We do not want to give advice, and we do not have solutions to offer, because at this point we want to direct our attention to this moment we are in and let it be or let us be in this moment. The analyses we offer are designed and performed as a way of 'staying with the trouble', which 'requires learning to be truly present, not as a vanishing pivot between awful or edenic pasts and apocalyptic or salvific futures, but as mortal critters entwined in myriad unfinished configurations of places, times, matters, meanings' (Haraway 2016: 1). This learning, we claim, is not about choosing adequate tactics or strategies, but about forming what might be a 'sensible attitude' (Haraway 2016: 4), which, as we propose, is linked to a rethinking of the ethical potentials embedded in discussions regarding fast and slow. The turn to ethics is linked to our effort to move and transform the very foundation for debates regarding the conditions of working in academia in the $21^{\text {st }}$ century by reconsidering a binary approach to fast and slow and introducing a new setting for thinking about speed, pace, and tempo in contemporary universities.

Throughout this article, we often mention ontological aspects of our inquiries, moreover, we closely link the ethical with the ontological. It is important to underline here that the turn to ethical thinking, rather than strategic or tactical, is from our perspective related to an ontological task - to create a 'sensible attitude' and 'stay with the trouble' (ibid.), as we need to consider the world in which this particular approach might be possible. We need to imagine the world in which the question of fastness and slowness might be reformulated. It is only through thinking ontologically, through reimagining the world, that we may also change the framework of the fast-slow debate in academia and offer a novel, ethical perspective. As Elizabeth Grosz underlines: 'all our actions presuppose a world, worlds, in which those actions are both viable and capable of signification and effectivity' (Grosz 2005: 128). As such, ethical actions that we develop in this paper need a world in which they matter.

We do not position ourselves as critics of the slow science movement; however, we are hesitant when noticing how slow universities and slow professors are merely presented as a response to fast science, and thus as intrinsically reactionary. By investigating the rules of the fast-slow dualism, we wish to reorient our attention to see the pitfalls and limitations on both sides of this binary and, simultaneously, by staying with the trouble, we seek to imagine things otherwise - beyond fast and slow conceived as oppositional stances. Disassembling oppositional thinking is a way of exploring in this article to pursue a pace of our own.

It is also worth stressing that we mobilise an affirmative reading of the slow science movement. We are by no means dismissive of such approaches, but want to think-with it, engage-with it based on what we consider our academic response-ability. We are well aware that, in the following deliberations, we do not cover every aspect of the slow science movement. As pointed out by Ewa Domańska in her opening keynote lecture, Slow Science and Emergent Methods in the Humanities and Social Sciences', the slow science movement emerged as a way to do justice to the quality and reliability of research and take responsibility for disseminating and understanding its outcomes and implications. Moreover, Domańska links slow academic initiatives with their critical potential, illustrating this with the example of an 'informal research centre' established in Warsaw in 2009: The Wolny Uniwersytet Warszawy (the Free/Slow University of Warsaw), guided by its slogan: "wolny, bo powolny" (freedom through slowness) (Domańska 2016). We do not address the inequalities between Western and Eastern Europe, Global South and

\footnotetext{
2 Throughout the article, we use words such as 'rhythm', 'pace', and 'tempo' interchangeably, although we are aware of the fact that each of them may point to a slightly different meaning. 'Pace' and 'tempo' are related to the question of velocity, whereas 'rhythm' refers to a certain regularity and repetition. According to Lefebvre and Régulier, however, it cannot be any repetition, but 'strong times and weak times, which return in accordance with a rule or law (...) recurring in a recognisable way (...) must appear in a movement' (2004: 78).

3 The fact that different paces and rhythms that shape and organize our working environment also form bodies, individuals, products of their work, etc. is far from a novel insight. The work of Michel Foucault (e.g. 1995 [1975]) on disciplinary society and Gilles Deleuze (e.g. 1996) on control society are just two examples of this trend.

${ }^{4}$ The keynote was given at the "7th Annual Conference on the New Materialisms. Performing Situated Knowledges: Space, Time, Vulnerability" in Warsaw on 21 September 2016.
} 
North, nor economic and class imbalances that matter especially with relation to academic positions (tenured or temporary) that reappear in the debates surrounding the slow science movement; not that we think them irrelevant in this context, but our priorities in this article lie elsewhere. Paying attention to the difficulties attached to the dualistic thinking about the academy is a way to shed new light on discussions about the pace of living an academic life in the current part of the $21^{\text {st }}$ century.

\section{TEMPORAL ONTOLOGIES OF THE UNIVERSITY}

As a response to 'the (fast) neoliberal university' - that is, the demand for an increasing working pace, a neverending series of reforms and changes, and the submission of all domains of university activity to principles of accounting and justification (Brown 2011: 113) - a cry to 'slow down' has surfaced, and manifestos for slow scholarship, slow reading, slow pedagogy, slow professors, have emerged (Berg and Seeber 2016, Mountz et al. 2015, Bird Rose 2013, Stengers 2011, The Slow Science Manifesto 2010, Alleva 2006).

The call to 'slow down' is a cry from (within) an academia that has picked up speed due to, possibly, forces of neoliberalisation and marketisation, as well as ongoing globalised reform practices. University reforms reconfigure time (Brøgger 2015) and reforms as travelling standards shape university practices of 'implementing' reforms and of leaving behind a past, fixing a future-to-come of 'deliverance' (Guyer 2007 in Brøgger and Staunæs 2016: 233):

Time is played staccato by these [reform] standards. Duration is shortened and intensified. Time passes quickly. Time is running and one can run out of time. You can lose time. Time goes by. Time is not coming. Time passes. Time is a scarce resource, so it needs to be taken care of and used in timely fashion. Time needs to be planned, calculated, ordered, and disciplined. Time is and needs to be economized. Time is consumed. Time is under pressure. Time is running out of breath. (Brøgger and Staunæs 2016: 232-233)

Academia lives through an 'ontology of calculation' (Brøgger and Staunæs 2016: 233, thinking with Guyver $2007^{5}$ ); a specific sort of present as futuring, conditioned by planning and calculating time. Brøgger and Staunæs report, based on interviews with academics, how reform processes cause nauseating affects as temporal ontologies collide through the bodies of the academics. In affective terms, losing time, wasting time, managing time, stealing time, time shortages, having no time - all come with fears, a sense of loss, unlive-able life in the world of 'emergency as rule' (Thrift 2000 in Gill 2009), which transforms scholars' lives into a state of constant alert, readiness to work, and availability - alertness becomes routine.

Nausea is only one example of how bodies react when overwhelmed by excessive stimuli. Other authors (e.g. Gill 2009) report different kinds of health problems, including chronic fatigue syndrome, burnout, exhaustion, insomnia, anxiety, and stress. It is possible to interpret this wide range of ailments using different theoretical approaches. On the one hand, as pointed out by Rosi Braidotti, we might understand such bodily reactions as how our bodies choose to convey a simple message to us: this is too much, 'one has reached the threshold of sustainability' (Braidotti 2006: 158-159). On the other hand, however, 'the individual is not only forming the neoliberal system ideologically, but they are also attuning to it organically' (Rogowska-Stangret 2017: 14). This can be exemplified using the work of Elizabeth A. Wilson on how, in cases of bulimia, 'the gag reflex itself may be attenuated' (Wilson 2004: 79) to the point where it disappears entirely. Both approaches attest to the fact that bodies do not only oppose neoliberal academia, but also collaborate with it and conform with the growing demands of academic life. After all, people do generally sleep less than previously (Crary 2013).

As noted by Sharon Traweek, even research results, as they are reported and published, contribute to what we may consider a compression of time, or an annulment of time. The results presented by the particle physicists in the United States and Japan studied by Traweek are tidied up to be 'free of ephemeral time' (1988: 157), even though: "In the course of a career a physicist learns the insignificance of the past, the fear of having too little time in the present, and anxiety about obsolescence in the face of a too rapidly advancing future" (Traweek 1988: 17). All the hard work that went into enabling 'results' (grant applications, experiments, data production and analysis, developing and dismissing theories, consulting with colleagues, engaging with other researchers' results, and so forth) is made invisible, 'at the end of the day or project, the product of the physicists' activity is freed from any marks of this work' (Schrader 2012: 119). These mechanisms do not apply solely to physicists, but resonate with, and might be also used to investigate, products of the work of researchers in other academic disciplines. This adds a layer of possible temporal dis-orientation in the lives of researchers, as the sense of the labour of the process may somewhat linger on as they move on to the next task, and the next, and the next.

\footnotetext{
${ }^{5}$ In her article "Prophecy and the near future: Thoughts on macroeconomic, evangelical, and punctuated time", Jane I. Guyver does not analyse academia, but reads diffractively through temporal perspectives within US macroeconomics and evangelical understandings of time; hence the point about calculation.
} 
One might say that the 'ontology of calculation' (Brøgger and Staunæs 2016: 233, thinking with Guyver 2007) colonises our futures, 'emergency as rule' (Thrift 2000 in Gill 2009) nullifies our presents, and our fixation on development, improvement, and reform obliterates our pasts. We do indeed have no time! The slow science movement is a response to these, and a number of other conditions of being of the university. When examining slow science, and the answers, solutions, remedies, and suggestions that it offers, however, we have found it to have certain limitations, and we therefore offer a respectful diffractive reading of the slow science movement.

\section{STAYING WITH THE SLOW OF THE SLOW SCIENCE MOVEMENT}

Many authors, such as Isabelle Stengers, Deborah Bird Rose, and the Great Lakes Feminist Geography Collective, to name just a few, recognise the problematic nature of fast science. While searching for solutions and tracing the contours of a revolution, they formulate a demand that academics be allowed to perform both slow and fast science, to change registers:

'I decided to divide my work into fast work and slow work. The two are not wholly separable, but the major difference, in my mind, is that fast work is strategic and slow work is dialogic' (Bird Rose 2013: 9);

'Don't get us wrong - we do say yes to the accelerated science of the early $21^{\text {st }}$ century. We say yes to the constant flow of peer-review journal publications and their impact; we say yes to science blogs and media \& PR necessities; we say yes to increasing specialization and diversification in all disciplines. [...] However, we maintain that this cannot be all' (The Slow Science Manifesto 2010);

'I am [...] aware that no university today is free to escape the rules that make fast, competitive, science a matter of life and death. That is why I wish [...] to emphasize the difference between, on the one hand, adhering to a rule and, on the other, recognizing its power while looking for the opportunities to experiment outside its bounds, creating interstices where another science could discover its own demands' (Stengers 2011: 12-13).

Thus, academics are encouraged to be 'smart' - to move within the bounds of the given possibilities, to manoeuvre past obstacles in order to accommodate the demands of both paces - fast and slow. We recognise these strategies as an effort to try to start from our current position, to adequately recognise the existing situation and, on this basis, search for possible ways of making a difference, for the sake of academic quality and out of a sense of responsibility for future generations and the world as such. The aforementioned authors often recognise a need for radical revolution and seek to establish conditions that enable actions, which might stimulate revolutionary potentials. This can be seen in Stenger's plea for slow science: 'Another science is possible!' or in the aims articulated by members of the Great Lakes Feminist Geography Collective: 'slow scholarship cannot just be about making individual lives better, but must also be about re-making the university' (Mountz et al. 2015: 1238), 'We argue for a fundamental restructuring of the university' (p. 1248), and 'the time is ripe for radical change' (p. 1249).

Nevertheless, doing both fast and slow science can also reaffirm the existing situation, maintaining it and collaborating with it; indeed, it means inscribing the slow with the demands and tempo of the fast or - better put - finding a slow disguise for the fast. We want to direct our attention to 'staying with the trouble' rather than finding a quick and easy solution, because any apparent solution, however caring and attentive its intentions, may be all too easily consumed by fast approach. As expressed by Michel Foucault: 'every strategy of confrontation dreams of becoming a relationship of power' (1983: 225-226).

This movement of covering up the 'fast approach' under a 'slow disguise' can be exemplified by good advice carefully considered, lived, and passed on by authors with the intention of helping other scholars manage their time and tackle the shift from fast to slow and vice versa. In For Slow Scholarship: A Feminist Politics of Resistance through Collective Action in the Neoliberal University (Mountz et al. 2015), academics are advised to: discuss and support the slow movement, include the invisible in evaluation processes (e.g. time spent on caring for others), organise collectively and create a community of slow scholars, emphasise care ('Do not shy away from talking about life, and how intertwined life and work are' (p. 1251)), write fewer emails ${ }^{6}$, stay offline (e.g. refuse to respond to emails at all hours), take time to think and to write (differently), say no when necessary, agree when there is an opportunity to bring about change and introduce slow strategies, become minimalist (i.e. 'good enough is the new perfect' (p. 1253)). Similarly, in Slow Professor: Challenging the Culture of Speed in the Academy, Maggie Berg and Barbara Seeber advise fellow scholars to, among other things: get offline, do less, organise 'regular sessions of timeless time', do

${ }^{6}$ See more advice on this particular issue here: http://emailcharter.org/. 
nothing, 'change the way we talk about time all the time', 'remember the values of density, complexity, and ideas which resist fast consumption', 'make time for (...) 'Unintentional Knowledge: what we find when we're not looking", 'take the time to read things that we do not 'have to' read', 'follow our hearts', 'keep calm and write on', vent from time to time to avoid whining, and 'risk candour'.

These pieces of advice might have been helpful at some stage (to draw attention to the accelerating academy and recognise its 'hidden injuries' (Gill 2009), thereby addressing what is excluded from the 'official' story about life in the academy) and they still might help us in managing our time in the fast academy, coping with the demand to speed up while being also critical of it. Most of the advice is written to help stimulate, introduce, and lay the foundations for a new academia; more responsible for futurity, more collaborative, healthier, more thoughtful, more caring, and with higher academic quality. This attempt to find niches where one is able to make a difference should be appreciated.

The questions that keep haunting us when dwelling on these matters are, however, numerous. In this article, we will limit our attention to focus on the claim - expressed in the aforementioned literature - that it is possible to do both-and. We want to consider bodies and rhythms, their im/possibilities and their ir/regularities, and the idea that it is (non-)humanly possible to shift between slow and fast at an ever-changing pace.

We ask: how is it possible to do both fast and slow science, and how quickly can we switch between these registers? What does it mean to change from fast to slow and vice versa? What does this change/ transformation look like? This is also linked to the question of conditions enabling changes: how can we introduce modifications, variations, or shifts at the organisational, political, institutional, or psychological level without repeating what is given or falling in pitfalls of the conditions we oppose?

\section{RHYTHMANALYSIS OF THE FAST-SLOW ACADEMIC LIFE}

Looking at university life (as a whole), it seems like it is not a question of a single transition between fast and slow. As multiple rhythms exist at any given time, there is an expectation of a human ability to rapidly 'switch' between and among rhythms; to be polyrhythmic, or even to harmoniously combine disharmonies, to be a kind of 'transition box' that changes 'arrhythmia' into 'eurhythmia' (Lefebvre 2004). So, let's stay with this idea of rhythms for a moment, to see what sort of explanatory/analytical power it may give to the tempo and fast-slow question.

Lefebvre writes that 'energy' is movement - it is that which enables interaction of time and space. Time, space, and energy are specifically formed through a rhythm - and through the relationships, differences, and specificities of co-existing rhythms - rhythms flowing through bodies and affecting them. Rhythms have spatial, material, bodily, and affective qualities. In developing rhythmanalysis, Henri Lefebvre works with subcategories such as 'polyrhythmia', 'eurhythmia', and 'arrhythmia'. This is relevant because it conceptualises the specificities of how rhythms may flow through, 'hit', and modulate the body. Arrhythmia is the term for the state of following conflicting rhythms. It means the dissonance between or among two or more rhythms. It is a sort of pathological state, where the multiplicity of rhythms produces 'fatal desynchronisation': a divergence in time, in space, and therefore in the use of energies (Lefebvre 2004: 68). Chronic fatigue syndrome, burnout, exhaustion, insomnia, anxiety, and the like, as mentioned earlier, are examples of what Lefebvre terms arrhythmia. Furthermore, if trying to follow his and Régulier's somewhat sketchy steps towards an alternative to psychoanalysis (rhythmanalysis as 'therapy', see Lefebvre, Régulier 2004), one can imagine how they might approach these conditions (exhaustion, insomnia, etc.) by addressing the multiplicities of rhythms and how they interfere and collapse. One could also think with this idea in terms of an 'individual' or 'dividual' matter, or one could think of it as an organisational or collective matter of sensing, addressing, and questioning disturbance patterns and affective qualities and specificities. This would then, in our imagination, be a specific space of staying with the troubles; that is, 'rhythmtherapy' as a space of being and unravelling, not 'solving'.

We are done by/parts of multiple rhythms at any given time. Some of the rhythms, our involvement is more 'direct'; others less so. For example, to be near the bodies of other people who either struggle with transitions or perhaps are (momentarily) stuck at one pace (speed-speed-speed) affects 'you' even though it is not (in a humanist sense) 'you'/your body. Your body and your nervous system does not end and begin at the borders of your own flesh (everybody is 'more than one and less than many' (Strathern 1991: 35 cited in Swanson et al 2015: 1507)). When you see the suffering of others, it hits your sensory registers. When listening to a voice that is tense with speed/stress, the sound waves of distress flow through 'your own' system. There are constant, multiple rhythms and movements that everybody is part of becoming with and of at any given time and place.

There is a conceptual play between movement and 'to be moved'; 'to be moved' in the sense to be affected, pushed, pulled beyond any control by the specific beats and rhythms. Being moved may be both energising and

\footnotetext{
${ }^{7}$ Strathern (1991), though, writes "One is Too Few but Two are Too Many" (p. 36), so probably Swanson et.al are the ones
} to be credited with the phrase. 
exhausting. So how much movement and what qualities of movement can our bodies bear? How many bodies may one be/become before it becomes too much? Addressing these questions is a matter of empirical, relational specificities, as the specificities of what may be sensed as slow and fast (and as 'too much') are a matter of what other movements and rhythms are around and interfere, interplay, diffract with others. There must be more rhythms of 'a' body (more bodies of one...?) in order to sense different paces. Following Barad (2007), one might say that it is a matter of the intra-actions (that always come to be as specificities); it is only possible to determine the quality in the agential separability, the 'cutting together apart' which is the agentially enacted material conditions of exteriority-within-phenomena (Barad 2014: 177). It is inherently relational - and multiple - while entangled in nature.

When thinking about the richness of the rhythms that percolate through us, a plethora of intra-actions that attest to the relational character of the world, the immensity of paces shaping the matter of life itself, we might want to pose a question of the (emotional, bodily, social, cultural, institutional, etc.) limits associated with this intense multitude, its regularities and irregularities (and their effects on us), and return to the 'slow movement' as a way to address relationalities, affectivities, and excessiveness of living an (academic) life. It is no coincidence that this cry for slowness arises. Lefebvre and Régulier state that, "We are only conscious of most of our rhythms when we begin to suffer from some irregularity" (Lefebvre and Régulier 2004: 77). So, as what is sensed is the acceleration - and its nauseating effects, among other things - an orientation towards questions of pace seems obvious, asking when and how 'speed' may be counteracted or combined with 'slowness'. But, still, what actions do switching between fast and slow involve? We tried to experiment with this question.

\section{SLOW AND SLOW-MOTIONING}

The video artist Bill Viola is famous for producing slow-motion film clips. We agreed to watch his work in order to try to engage with what slow-motioning might be like as art, as a metaphor, as a practice, as bodily becoming - that is, as becoming bodily while watching the video art $^{8}$.

A very short presentation of the works we watched is appropriate at this juncture. The first is entitled The Raft (Viola 2004) and is a 10-minute piece showing a group of people, positioned as if waiting at a bus stop, each minding their own business; they are strangers to each other. Suddenly, a large, forceful stream of water is directed at them, coming from the sides, totally engulfing them. Some manage to stand on their feet; others are forced to let themselves fall to the ground. They are turned into a sort of collective entity of water-bodies for a while, and then the water becomes still and the viewer sees them return to their senses, some helping others get back up, some hugging one another, some standing alone, before leaving the scene one by one. The whole sequence occurs in slow motion - displaying every bodily micro-movement and micro-expression and the changes in the emotional expressions writ upon the group's faces, from bored to shocked to despair. The other piece we watched is not Viola's own work, but was created by the art collective We Are Frilly (http://wearefrilly.com/blog/2013/9/10/faces-a-bill-viola-experiment) and called Faces - a Bill Viola experiment. This film lasts half an hour and shows 26 people, one by one, placed in front of the camera and then filmed whilst their families and friends provoked reactions from them. The video only displays the 'models' and, as the soundtrack is also slowed down, the atmosphere of the soundscape is strange, metallic, robotic/monstrous, unearthly, and definitely not human-like. Each encounter lasts approximately $1 \frac{1}{2} 2$ minutes, and we are faced with people of different ages and genders, as well as ethnic-racialised differences.

We watched these two pieces at different occasions. And we discovered that our bodily and psychological ability to watch - that is, of staying with the slow-motioning - was quite determined by when we watched the films. Watching before summer holidays and watching a month after finishing the holidays resulted - as one of us reported - in 'the urge to speed up the films and checking emails, open a newspaper, think about other duties' and there appeared to be a 'need to cover the film with layers that will speed it up: I'm thinking of something else, switching off, dropping off, detaching myself from the pace I cannot bear. Otherwise there emerged a feeling of both organic disorder and psychological distress'. Another mode of watching slow motion was to feel overwhelmed by the obligation to do so - and, as a result, one of us gave up the project and stopped watching the films.

Watching just after holidays, meanwhile, enabled a different intra-action of video and body. One of us experienced that with the film Faces - while before her holidays she could only bear to watch the film for less than 2 minutes, afterwards, she was able to watch the whole 30 minutes, even feeling that it could have lasted longer.

\footnotetext{
8 We picked two films: The Raft (2004: https://vimeo.com/13920952) by Bill Viola and Faces (2013: https:/ / www.youtube.com/watch?v=gD07j1ZIrw8) by the We Are Frilly collective.
} 
The other still rushed the watching, but now out of an eagerness to begin working on this article (somewhat ironically...)!

The point here is not to analyse our individual working lives (nor is it to perform an organisational analysis of the different tasks involved in an academic career, with all its specificities - including carefully addressing the inequalities between Western and Eastern Europe, Global South and North, these areas have economic and class imbalances that are effected by different academic positions (tenured or temporary)), but to consider the fast/slow dualism, heed the cry for a slowing down - and the conditions of im/possibility of transformation - it seems that the idea of this ability to shift from fast to slow and back is founded on a dualist premise, that of two separate entities of being. Switching without transitions or transformations, gaps or overlaps, what would it mean to push this fast-slow dualism to the extreme? Would doing so reveal the imperceptible nature of movement? Our experiment suggests an im/possibility of switching, i.e. an im/possibility to simply redirect attention from fast to slow, from slow to fast, without the slowness lingering in the fast-mode and without speeding up that stays in the background when slowing down. How voluminous are we ('actually') in terms of transitions (if considering fast/slow not to be entities or opposites, but instead, as ontologically entangled)? How many rhythms are we capable of embracing without falling into 'morbid and then fatal de-synchronisation' (Lefebvre 2004: 68)? What enables transition? What happens at the point of transformation? How is it possible?

Slow-motioning plays with the fluidity, imperceptibility, and infinity of movement; it opens up a space to zoom in on the moment of transition, to have a sense of what eludes our perception. Speeding up has similar effects speeding up transforms the fluidity, imperceptibility, and infinity of movement into lines. Becoming, as explained by Gilles Deleuze and Félix Guattari, has its ends in becoming imperceptible: 'one is no longer anything more than an abstract line' (Deleuze, Guattari 2007 [1980]: 280). From this perspective, fast and slow are indistinguishable. It opens the possibility of being both 'below and above the threshold of perception' (Deleuze, Guattari 2007 [1980]: 281). So, let's zoom in closer on the points of transition.

Another mode of investigating is to consult the technical aspects of slow-motioning - what does it actually entail, to slow motion when producing moving images, be it film or video? According to the Danish film director and producer Kristoffer Nyholm, when shooting for use in slow motion sequences, you need to record at a quality enabling an extra amount of images per second so that the subsequent slow motioning will be smooth. In a film, one second of footage consists of 24 images; as such, a movement can be said to comprise a specific number of images. When shooting for slow motion, however, one needs to create more images of the movement, even as many as 200-300 images per second (depending on the level of slowness one wants to accomplish). One then plays the movement/activity with a standard film image per second of 24 images, prolonging the movement. Effectively, this second is then a different sort of second as its relation to the viewer's sense of movement-second is out of sync within the sequence. (With a smaller amount of still images to work with, you get lower quality slowmotioning, as the individual image is 'stretched' in time, which results in distortion of the images, visible to the keen eye) (Nyholm in personal conversation 2017). Understood metaphorically, then, slow-motioning is not a process of simply rewinding and slowing down what was filmed; nor is the common-sense understanding of slowmotioning as simply doing something more slowly than normal accurate. In Nyholm's words, one is able to register lapses, or temporal between-nesses. Slow motion is then not a matter of recreation, but a re-creation; to enable slow motion is to open for a state of intense awareness: an intake of 'more' - not of 'the same' at a slower pace. It is an extreme intensity of being (that one is not supposed to sense in the first place), an added spatio-temporalaffective being that one may not be able to digest, depending on which other rhythms one is becoming of at that

\footnotetext{
${ }^{9}$ At a late stage in the process of writing this article, we discovered an article entitled Spacing organization: non-representational theory and performing organizational space by Timon Beyes and Chris Steyaert, influenced by The Raft. It is interesting as it attests to an altered sense of being as an effect of watching the film. Beyes and Steyaert write: "I take a deep breath when I remember the deep breath I took when this video was over. I felt stirred up, and so did the other viewers in the dark museum room who only slowly left for the next part of the exhibition. I walked out conscious of my own walking, my own mood and my own sensation of the dark room. As if I wanted to walk in slow motion. Yet my body walked me through the corridor without running into anybody else and into the garden of the museum from where you could see how calm the sea was on that day. Some of these feelings of intensity come back on this rather quiet afternoon, where my colleagues have in the meantime returned from lunch. Viola provides 'turbulent surfaces' in which emotional and physical shape coincide in arcs of intensity (Thrift 2004: 73). When I reread my own text [describing the video and the bodily and spatial experience in relation to watching it], my finger goes to the delete-key, as I think this description is too meager to suggest something of the ecstasy of the slowly turning narrative Viola produced in image and sound. Something blocks in my finger, and, with a sigh, I pass through my office door, in a hurry to get a sandwich" (Beyes \& Steyaert 2012: 47). This account is also interesting for the hunches of the $\mathrm{im} /$ perceptibility of transformation between speed and slowness that we are investigating in this article. Beyes and Steyaert (implicitly) address the temporal entanglements of an intense bodily experience; the deep breath reaction of two different spatio-temporal moments, the re-sensing of the event.
} 
moment in time ${ }^{10}$. In that sense, this way of considering slow-motioning also disturbs the dualist understanding of slow and fast: the slow is fast in its 'muchness' and the fast is slow in the sense that it is skirting through events (images, movements, meanings, sensations) in ways that are not engaging, or may only engage through gaps of presence.

\section{GAPS OF (NON-)PRESENCE}

Let's consult Bill Viola on the matter. In his talk Cameras are Soul Keepers ${ }^{11}$, he states that the fluidity of movement is enabled by a gap: 'there's a gap of empty space $[\ldots]$ there's an emptiness $[\ldots]$ real thing that exists: $[\ldots]$ the space between all physical objects'. But then, what is this space in-between, the emptiness - that real thing? How to link this emptiness with the fluidity/imperceptibility/infinity of movement? When approaching these questions, Karen Barad (2012) can offer inspiration as she considers the very nature of nothingness - carefully and thoughtfully, recognising the vulnerability of attempting to approach nothingness. Barad argues that the problem of nothingness is linked to indeterminacy. Quantum field theory does not allow the vacuum (or the void) to be 'determinately nothing because the indeterminacy principle allows for fluctuations of the quantum vacuum' (Barad 2012: 9), which means that emptiness is not the ontological character/being of nothingness. There is thus no (determined) empty space. Emptiness is a sort of play with its own condition - on the verge of emptiness and plentitude, it fluctuates between nothingness and allthingness, as there is an infinite number of im/possibilities of intra-actions of the void. The fluctuating vacuum is 'doing its own experiments with non/being' (p. 8), 'the void is a lively tension, a desiring orientation towards being/becoming' (p. 13). We may comprehend it in terms of virtuality, as stated by Barad: "Virtuality is [...] the indeterminacy of being/nonbeing, a ghostly non/existence" (p. 12). Virtuality embraces what is actualised, like 'a 'cloud' of an indeterminate number of virtual particles' (p. 15) that forms an electron. There is no sheer possibility of nothingness as full, determined emptiness; rather, it is filled with what might come to existence, be actualised, or realised. This forms an ontological ground for being open towards the difference, change, transition but also for infinite potentialities to embrace all different paces, tempos, velocities - to become polyrhythmic.

\section{TOWARDS AN ETHICS OF BE/COMING POLYRHYTHMIC}

To return to the question of how to change registers, we may say that 'pure' slowing down and speeding up are impossible. The fast and slow are both ungraspable and both 'below and above the threshold of perception' (Deleuze, Guattari 2007 [1980]: 281). As such, the question to be asked in terms of fast and slow academia is not how to manage time to do both, how to deal with that, how to approach it tactically, or use oneself to handle contradictory requirements, but instead, how to encourage oneself to embrace the virtuality - below and above oneself, how to experiment with im/possibilities, with non/being, so that we could not 'react differently to different [conditions, in the original: probings] but be differently' (Barad 2012: 6).

Importantly, this is not a return to a vision of academics required to synchronise arrhythmia into eurhythmia. We are talking here of embracing the virtualities of every rhythm to be or become polyrhythmic. This time, however, it is an ethical project, because in our view, the (arguments of the) slow movement is situated within the same ontology as the temporal ontology of the (neoliberal) university. It is about 'finding time', it is imposing with its demands on academics to manage time manage oneself, smarter. It is a remedy. It is about taking medication; it is a piece of advice and not a transition. What we find lacking, and what we would like to offer instead of advice, is a call to stay at the ontological level, a call for ethics. We do not need to use the same - already crazy - time better. We need ethics to form and cherish our polyrhythmic bodies.

As mentioned at the beginning of this article, we consider dwelling upon im/perceptibilities of fast-slow transformations (within the current climate of struggling to live liveable feminist academic lives) and staying at an ontological level that enables ethical and not tactical thinking. Working on this very paper - mostly through Skype conversations - was also a way of staying with the trouble of being and working in different cities, universities, together and alone, confronted with dissimilar life circumstances, faced with varying personal and professional challenges, manoeuvring our calendars to be able to meet online and engage with thinking together, making efforts to meet the deadlines and requests of our editors and reviewers, patiently assisting one another in 'stuck places'

\footnotetext{
${ }^{10}$ As such, a movie could, in Russian filmmaker Andrei Tarkovsky's words be sensed to be the ability to create time within time: "The cinema image comes into being during shooting, and exists within the frame [...] Editing brings together shots which are already filled with time, and organizes the unified, living structure inherent in the film; and the time that pulsates through the bold vessels of the film, making it alive, is of varying rhythmic pressure" (Tarkovsky 1989: 114).

11 (From Louisiana Channel: http://channel.louisiana.dk/video/bill-viola-cameras-are-keepers-souls; it starts around minute $4: 50)$.
} 
(Lather 1998), sharing our struggles and joys, infecting one another with laughter and tears, affecting each other with different rhythms and paces, trying to materialise - in this very piece of writing - the pace of our own. Neither fast, nor slow. Just our own.

To ponder for a moment over our experiment with our reactions to Bill Viola's video art: both reports attest to the fact that the affective experience is unmanageable; it does not coincide with our expectations, willingness, or plans. Slow-motioning confronted us with the unmanageable; with what eludes the tactical approach, showing that it is impossible to smoothly shift registers from fast to slow science and vice versa. It moreover confirms the affective nature of the experiment itself. As claimed by Gregory J. Seigworth and Melissa Gregg in their An Inventory of Shimmers, 'affect is integral to a body's perpetual becoming (always becoming otherwise, however subtly, than what it already is), pulled beyond its seeming surface-boundedness by way of its relation to, indeed its composition through, the forces of encounter. With affect, a body is as much outside itself as in itself - webbed in its relations - until ultimately such firm distinctions cease to matter' (2010:3, emphasis in original). This perspective makes it apparent that clear-cut distinctions are indeed impossible and that the body and its seeming outside are simultaneously moved and move affectively, and it is impossible to determine beyond doubt which forms of becoming are desirable and which are not, which movement is slow and which is fast, which affect leads to slow science and which results in the fast approach. When attempting to address the question of pace within academia using fast-slow dualism, we overlook the affective aspect of living an academic life - ripe with unmanageable, imperceptible, indecisive, subtle 'becoming otherwise'. Furthermore, through insights from the technical aspects of slow-motioning in video and movie production, we addressed the ontological being of slow motion as a state of intense awareness: an intake of 'more' - not of 'the same' at a slower pace. We struggled to zoom in on the possibility of change and transformation and diagnosed, with Barad, that the emptiness that - as stressed by Viola - is a prerequisite for change, is never empty. On the contrary, it is filled with infinite potentialities of change, thus reformulating the question of smooth transformation into a question of embracing different modalities, $\mathrm{im} /$ possibilities, paces. Hopefully, it also hints at possible aspects - and challenges - of what learning 'to be truly present' (Haraway 2016: 1) could entail in academic life and which new approaches might emerge (enabling modifications at the organisational, political, institutional, psychological levels) instead of 'only' engaging in attempts to manage time, affects, and plans for the future (which, as we sought to demonstrate, merely reaffirms the status quo and fails to avoid the pitfalls of the conditions we oppose) ${ }^{12}$. This might be a good starting point to think ethics of living (academic) lives and to allow the polyrhythmic multitude of ourselves/bodies be(come) different; for the sake of not just our bodies, but the bodies that are constantly impacted by the vibrations rushing through our bodies.

\section{REFERENCES}

Alleva, L. (2006). Taking time to savour the rewards of slow science. Nature, 443, 271 (21 September). Available at: http://www.nature.com/nature/journal/v443/n7109/full/443271e.html. (Accessed 27 July 2017).

Barad, K. (2007). Meeting the Universe Halfway: Quantum Physics and the Entanglement of Matter and Meaning, Durham, NC: Duke University Press.

Barad, K. (2012). What Is the Measure of Nothingness? Infinity, Virtuality, Justice/ Was ist das Maß des Nichts? Unendlichkeit, Virtualität, Gerecbtigkeit, Documenta 13, 99, Kassel: Hatje Cantz.

Barad, K. (2014). Diffracting Diffraction: Cutting Together-Apart. Parallax, 20(3), pp. 168-187. https://doi.org/10.1080/13534645.2014.927623

Barad, K. (2016). Troubling Time/s: Undoing and Re-membering The Future, The Future Lecture Series, 25.10.2016, Aarhus University.

Berg, M. and Seeber, B.K. (2016). The Slow Professor: Challenging the Culture of Speed in the Academy. Kindle edition. Toronto: University of Toronto Press.

Bergson, H. ([1986] 2004). Matter and Memory. 5th ed., Transl. N.M. Paul and W.S. Palmer, Mineola, NY: Dover.

Beyes, T and Steyaert, C. (2012). Spacing organization: non-representational theory and performing organizational space. Organization, 19(1), pp. 45-61. https://doi.org/10.1177/1350508411401946

Bird Rose, D. (2013). Slowly writing into the Anthropocene, TEXT Special Issue 20, M. Harrison, D. Bird Rose, L. Shannon, K. Satchell (eds). Available at: http://www.textjournal.com.au/speciss/issue20/Rose.pdf. (Accessed 27 July 2017).

Braidotti, R. (2006). The Ethics of Becoming Imperceptible. In: C. Boundas, ed., Delenze and Philosophy (pp. 133159). Edinburgh: Edinburgh University Press.

\footnotetext{
${ }^{12}$ We are paraphrasing Haraway's words. Obviously, Haraway is engaged in very different processes than we are here, and we do not intend to disrespect or to disturb the specificities of the political intensity and impact that her phrase is designed to have.
} 
Brown, W. (2011). Neoliberalized Knowledge. History of the Present: A Journal of Critical History, 1(1), pp. 113-129. Available at: http://interimprovost.ucdavis.edu/local_resources/docs/20150520/Brown_NeoliberalizedKnowledge.pdf (Accessed 27 July 2017).

Brøgger, K. (2015). The faceless master of higher education. New Standards - New Normals. Educational Standards in the (Un)making. The case of higher education reform. PhD Dissertation. Copenhagen: Aarhus University.

Brøgger, K. and Staunæs, D. (2016). Standards and (self)implosion: how the circulation of affects accelerates the spread of standards and intensifies the embodiment of colliding, temporal ontologies. Theory \& Psychology, 26(2), pp. 223-242. https:// doi.org/10.1177/0959354316635889

Crary, J. (2013). 24/7: Late Capitalism and the Ends of Sleep. London: Verso.

Deleuze, G. (1996). Negotiations 1972-1990. New York: Columbia University Press.

Deleuze, G. and Guattari, F. (2007 [1980]). A Thousand Plateaus: Capitalism and Schizophrenia. Transl. B. Massumi. Minneapolis: University of Minnesota Press.

Dolphijn, R. and van der Tuin, I. (2012). New Materialism: Interviews \& Cartographies. Ann Arbor: Open Humanities Press.

Domanska, E. (2016). Slow Science and Emergent Methods in the Humanities and Social Sciences, opening keynote lecture at the "7th Annual Conference on the New Materialisms. Performing Situated Knowledges: Space, Time, Vulnerability" in Warsaw on 21 st September 2016.

Foucault, M. (1983). The Subject and Power. In: H.L. Dreyfus and P. Rabinow, eds., Michel Foucault: Beyond Structuralism and Hermeneutics, (pp. 208-252). Chicago: The University of Chicago Press.

Foucault, M. (1995 [1975]). Discipline and Punish. The Birth of the Prison. Transl. A. Sheridan. New York: Vintage Books.

Gill, R. (2009). Breaking the silence: The hidden injuries of neo-liberal academia. In: R. Flood and R. Gill, eds., Secrecy and Silence in the Research Process: Feminist Reflections (pp. 228-244). London: Routledge.

Grosz, E. (2005). Time Travels. Feminism, Nature, Power. Durham, London: Duke University Press.

Guyer, J.I. (2007). Prophecy and the near Future: Thoughts on Macroeconomic, Evangelical, and Punctuated Time. American Ethnologist, 34(3), pp. 409-421. https://doi.org/10.1525/ae.2007.34.3.409

Haraway, D. (2016). Staying with the Trouble: Making Kin in the Chthulucene. Durham, London: Duke University Press.

Lather, P. (1998). Critical Pedagogy and its Complicities: A Praxis of Stuck Places, Educational Theory, 48(4), pp. 487-497. https://doi.org/10.1111/j.1741-5446.1998.00487.x

Lefebvre, H. (2004). Elements of Rhythmanalysis: An Introduction to the Understanding of Rhythms. In: Rhythmanalysis. Space, Time and Everyday Life (pp. 1-69). Transl. S. Elden and G. Moore, New York, London: Continnuum.

Lefebvre, H. and Régulier, C. (2004). The Rhythmanalytical Project. In: Rhythmanalysis. Space, Time and Everyday Life (pp. 71-83). Transl. S. Elden and G. Moore, New York, London: Continnuum.

Mountz, A., Bonds, A., Mansfield, B., Loyd, J., Hyndman, J., Walton-Roberts, M., Basu, R., Whitson, R., Hawkins, R., Hamilton, T., Curran, W. (2015). For Slow Scholarship: A Feminist Politics of Resistance through Collective Action in the Neoliberal University. ACME: An International E-Journal for Critical Geographies, 14(4), pp. 12351259. Available at: https://www.acme-journal.org/index.php/acme/article/view/1058/1141 (Accessed 27 July 2017).

Nyholm, K. in personal conversation with Malou Juelskjær, Copenhagen, 29 th May, 2017 (and 19th December 2016).

Rogowska-Stangret, M. (2017). Sharing Vulnerabilities. Searching for "unruly edges" in times of the neoliberal academy. In: B. Revelles-Benavente and A.M. González Ramos, eds., Teaching Gender. Feminist Pedagogy and Responsibility in Times of Political Crisis (pp. 11-24). London, New York: Routledge.

Schrader, A. (2012). Haunted Measurements: Demonic Work and Time in Experimentation. Differences: A Journal of Feminist Cultural Studies, 23(3), pp. 119-160. https:/ / doi.org/10.1215/10407391-1892916

Seigworth, G.J. and Gregg, M. (2010). An Inventory of Shimmers. In: G.J. Seigworth and M. Gregg, eds., The Affect Theory Reader (pp. 1-25). Durham, London: Duke University Press.

Stengers, I. (2011). "Another science is possible!" A plea for slow science. [online] Available at: http://we.vub.ac.be/aphy/sites/default/files/stengers2011_pleaslowscience.pdf. (Accessed 27 July 2017).

Strathern, M. (1991). Partial Connections. Savage, MD: Rowman and Littlefield.

Tarkovsky, A. (1989). Sculting in Time: Reflections on the Cinema. Transl. K. Hunter Blair. Austin, TX: University of Texas Press.

Swanson, H.A., Bubandt, N. and Tsing, A. (2015). Less Than One But More Than Many: Anthropocene as Science Fiction and Scholarship-in-the-Making. Environment and Society: Advances in Research 6(1), pp. 149-166. https://doi.org/10.3167/ares.2015.060109

The Slow Science Manifesto (2010). http://slow-science.org/. By: (c) The Slow Science Academy, 2010. Berlin, Germany. 
Thrift, N. (2000). Performing cultures in the new economy, Annals of the association of American Geographers, 90, pp. 674-692. https://doi.org/10.1111/0004-5608.00217

Traweek, S. (1988). Beamtimes and Lifetimes: The World of High Energy Physicists. Cambridge, MA: Harvard University Press.

Wilson, E.A. (2004). Gut Feminism. Differences. Journal of Feminist Cultural Studies, 15(3), pp. 66-94. https://doi.org/10.1215/10407391-15-3-66

Citation: Juelskjær, M. and Rogowska-Stangret, M. (2017). A Pace of Our Own? Becoming Through Speeds and Slows - Investigating Living Through Temporal Ontologies of The University. Feminist Encounters: A Journal of Critical Studies in Culture and Politics, 1(1), 06. https://doi.org/10.20897/femenc.201706

Copyright (C) 2017 by Author/s and Licensed by Lectito BV, Netherlands. This is an open access article distributed under the Creative Commons Attribution License which permits unrestricted use, distribution, and reproduction in any medium, provided the original work is properly cited. 